\title{
Efficacy and safety of AZD7594, an inhaled non-steroidal selective glucocorticoid receptor modulator, in patients with asthma: a phase 2 a randomized, double blind, placebo-controlled crossover trial
}

\author{
Mary N. Brown ${ }^{1 *}$ (D, Rainard Fuhr ${ }^{2}$, Jutta Beier ${ }^{3}$, Hong-Lin Su ${ }^{4}$, Yingxue Chen ${ }^{5}$, Henrik Forsman ${ }^{7}$,
} Ulrika Wählby Hamrén ${ }^{6}$, Helen Jackson ${ }^{8}$ and Ajay Aggarwal ${ }^{1}$

\begin{abstract}
Background: Inhaled corticosteroids reduce inflammation in asthma but chronic use may cause adverse effects. AZD7594, an inhaled non-steroidal selective glucocorticoid receptor modulator, has the potential of an improved risk-benefit profile. We investigated the safety and efficacy of AZD7594 in asthma.

Methods: This phase 2a multi-center, randomized, double-blind, placebo-controlled crossover study enrolled adults with asthma aged 18 to 75 years. Patients were treated with budesonide $200 \mu \mathrm{g}$ twice daily for 2-3 3 weeks (run in part one). If controlled, as demonstrated by an asthma control questionnaire- 5 score of $<1.5$, patients entered a three-week run-in (part two) where they received a short acting bronchodilator alone. Thereafter, patients with a fractional exhaled nitric oxide $\left(\mathrm{F}_{\mathrm{E}} \mathrm{NO}\right) \geq 25 \mathrm{ppb}$ and pre-dose $\mathrm{FEV}, 40$ to $90 \%$ predicted were randomized to one of nine treatment sequences. Each patient received placebo and two of three dose levels of AZD7594 (58, 250, $800 \mathrm{\mu g}$ ) once daily via inhalation, in 14-day treatment periods, separated by three-week washout periods. The primary endpoint was the change from baseline in morning trough $\mathrm{FEV}_{1}$ versus placebo on day 15 . Secondary endpoints included measures of airway inflammation and asthma control.
\end{abstract}

Results: Fifty-four patients were randomized and received at least 1 dose of treatment, 48 patients completed the study. Overall 52 patients received placebo, 34 received AZD7594 $58 \mu \mathrm{g}$, 34 received AZD7594 $250 \mu \mathrm{g}$, and 34 received AZD7594 $800 \mu \mathrm{g}$. AZD7594 $800 \mu \mathrm{g}$ demonstrated a significant improvement in Day 15 morning trough FEV ${ }_{1}$ versus placebo (LS means difference $0.148 \mathrm{~L} \mathrm{95 \%} \mathrm{Cl} \mathrm{0.035-0.261,} p=0.011$ ), with a dose-dependent response seen in the $250 \mu \mathrm{g}(0.076 \mathrm{~L}-0.036-0.188, p=0.183)$ and $58 \mu \mathrm{g}(0.027 \mathrm{~L}-0.086-0.140, p=0.683)$. All secondary endpoints showed statistically significant improvement at the $800 \mu \mathrm{g}$ dose. All doses demonstrated a significant reduction in $\mathrm{F}_{\mathrm{E}} \mathrm{NO}$ at day $15 p<0.01$. No statistically significant difference in plasma cortisol level was observed between AZD7594 and placebo at any dose. AZD7594 was considered safe and well tolerated.

Conclusions: Two-week treatment with AZD7594 demonstrated a favorable risk-benefit profile in patients with mild to moderate asthma. Further clinical studies are needed to fully characterize AZD7594.

Trial registration: ClinicalTrials.gov number NCT02479412.

Keywords: Asthma, Inhaled corticosteroids, Selective glucocorticoid receptor modulator, Pharmacokinetics, Cortisol

\footnotetext{
* Correspondence: mary.brown@astrazeneca.com

${ }^{1}$ Respiratory, Inflammation and Autoimmunity Translational Medicine Unit, Early Clinical Development, IMED Biotech Unit, AstraZeneca, 35 Gatehouse Drive, Waltham, MA 02451, USA

Full list of author information is available at the end of the article
}

(c) The Author(s). 2019 Open Access This article is distributed under the terms of the Creative Commons Attribution 4.0 International License (http://creativecommons.org/licenses/by/4.0/), which permits unrestricted use, distribution, and reproduction in any medium, provided you give appropriate credit to the original author(s) and the source, provide a link to the Creative Commons license, and indicate if changes were made. The Creative Commons Public Domain Dedication waiver (http://creativecommons.org/publicdomain/zero/1.0/) applies to the data made available in this article, unless otherwise stated. 


\section{Background}

Asthma is characterized by chronic inflammation and glucocorticoid receptor (GR) agonists as inhaled corticosteroids (ICS) are the preferred anti-inflammatory treatment at all asthma severity levels [1]. ICS alone and in combination with long acting beta adrenergic agonists (LABAs) have demonstrated improvement in symptoms and lung function, reduction in exacerbations, improved asthma control and quality of life [2-4]. As ICS are administered topically and have low systemic absorption, the major limitation for ICS therapy is the risk of local adverse effects including candidiasis and dysphonia which are inconvenient for the patient, but typically not serious in nature. ICS therapy has the potential to cause systemic adverse effects mediated by the hypothalamic-pituitary-adrenal (HPA) axis, such as a reduction of growth velocity in children $[5,6]$ and effects on bone mineral density [7] although this effect is less clear [8]. Systemic effects are less common and usually associated with chronic use of high doses $[9,10]$.

Several development programs have aimed to improve selectivity for the glucocorticoid receptor to preserve efficacy while reducing adverse effects. Four compounds prior to AZD7594 have advanced to clinical trials in asthma [11], but none have advanced beyond phase 2 trials.

AZD7594 is a novel nonsteroidal, potent and selective glucocorticoid receptor modulator (SGRM) being developed as a once daily inhaled treatment for asthma. Pre-clinical data using the Rat Sephadex ${ }^{\circ}$-induced lung edema model of pulmonary inflammation supports an improved therapeutic ratio when delivered by inhalation [12]. In this phase 2 a randomized study, the first to evaluate clinical efficacy, we aimed to assess the efficacy, safety, and pharmacokinetics (PK) of AZD7594 given once daily by inhalation in adults with asthma uncontrolled on short acting beta agonists (SABAs) alone. We investigated the effect of AZD7594 on morning trough $\mathrm{FEV}_{1}$, airway inflammation, and measures of asthma control. Some results of this study were presented at the European
Respiratory Society meeting in $2017,[13,14]$ this paper provides the complete results from the study.

\section{Methods \\ Study design}

This phase 2 randomized, double-blind, multi-dose, placebo controlled, three-period, incomplete block crossover study was conducted in nine centers in Germany and one center in Bulgaria between June 25, 2015 and February 8, 2016 (Fig. 1).

\section{Patients}

Eligible patients were men and women of non-child bearing potential 18 to 75 years of age with mild to moderate asthma. Patients must have had a documented clinical diagnosis of asthma at least 6 months prior to enrollment and were either steroid naïve or treated with monteleukast, ICS or low dose ICS / LABA. Current or recent smokers (who quit within the last 6 months) and patients with $\geq 10$ years total smoking history were excluded. Patients were required to have a fraction of exhaled nitric oxide $\left(\mathrm{F}_{\mathrm{E}} \mathrm{NO}\right)$ level $\geq 25$ parts per billion $(\mathrm{ppb})$ before randomization, demonstrating evidence of airway inflammation. Full inclusion and exclusion criteria are provided in the Additional file 1: appendix.

\section{Randomization and masking}

Eligible patients were randomized via an interactive voice response system prior to the first dose in treatment period one, to one of nine treatment sequences according to the randomization schedule produced by independent PAREXEL Informatics. Each treatment sequence included two out of three possible treatments: AZD7594 $58 \mu \mathrm{g}$, AZD7594 $250 \mu \mathrm{g}$, AZD7594 $800 \mu \mathrm{g}$, and each patient received placebo during one of the three periods in a balanced crossover design. The study was performed in a double-blind manner. Placebo was supplied as identical dry powder vehicle to AZD7594 in identical packaging,

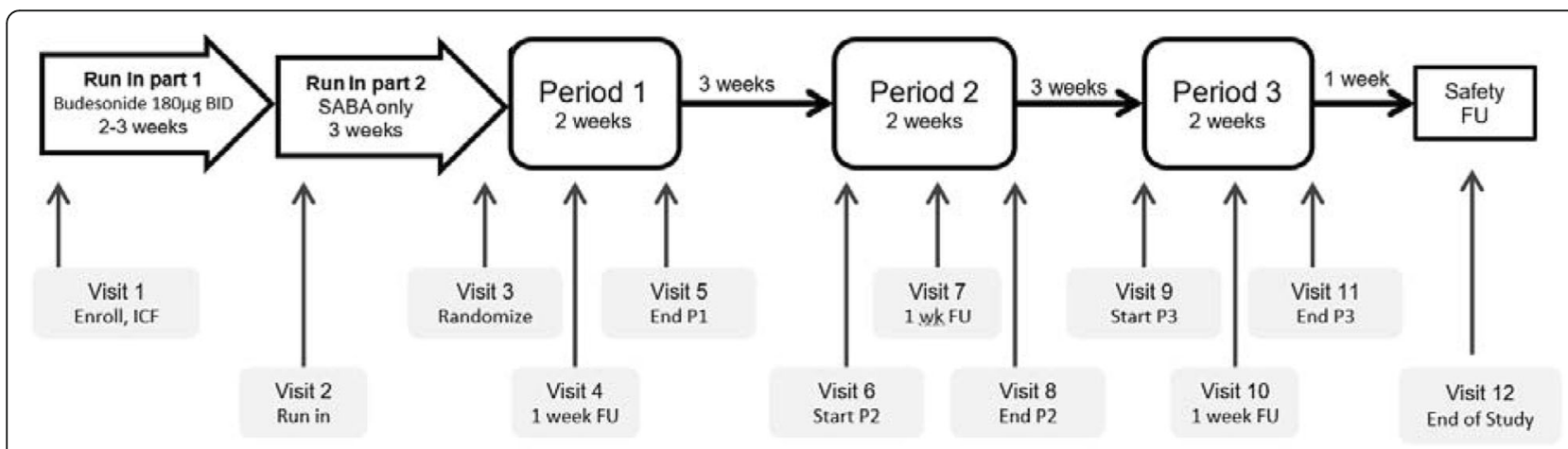

ICF informed consent form, FU follow-up, P period, SABA short acting $\beta$ - 2 agonist

Fig. 1 Trial design 
and budesonide (used during run-in) and salbutamol (rescue medication) were open label.

\section{Treatment}

During a two to 3 week run-in (part one) patients received low dose budesonide ( $200 \mu \mathrm{g}$ twice daily). Patients whose asthma was controlled (as demonstrated by an Asthma Control Questionnaire-5 [ACQ-5] score $\leq 1.5$ ), were eligible for a second run-in (part two) during which budesonide was stopped and washed out over 3 weeks while patients received only the SABA, salbutamol, as needed. At the end of the second run-in, patients with pre-bronchodilator forced expiratory volume in 1 second $\left(\mathrm{FEV}_{1}\right)$ between 40 to $90 \%$ and with a $\mathrm{F}_{\mathrm{E}} \mathrm{NO}$ of $\geq 25$ ppb were randomized and entered the double-blind treatment period. Patients who were poorly controlled as evidenced by rescue medication use of $\geq 12$ puffs on three or more days or an ACQ- $5 \geq 3$ during the enrollment period were excluded. Randomized patients received study medication once daily by inhalation via a monodose dry powder inhaler (DPI) for a 2 week treatment period. Each treatment period was separated by a three-week washout, where the only asthma treatment that patients received was as needed salbutamol. A stability criterion was applied at baseline of treatment periods 2 and 3 to ensure that there was no detectable carry-over effect or any acute worsening compared to baseline at the start of those periods. Patients were evaluated to confirm that the pre-dose $\mathrm{FEV}_{1}$ was $\pm 20 \%$ of the pre-dose baseline value for treatment period 1 .

\section{Endpoints}

The primary efficacy endpoint was change from baseline in morning trough $\mathrm{FEV}_{1}$ on Day 15 versus placebo for each of the three AZD7594 dose levels. Baseline was defined as the average of the measurements obtained at 60 and $30 \mathrm{~min}$ before dosing on day 1 in each treatment period, and trough as the average of the 2 spirometric measurements at 23:00 and 23:30 h after the last dose of study medication on Day 14 . Spirometry was assessed centrally.

Secondary efficacy endpoints included change from baseline in: $\mathrm{F}_{\mathrm{E}} \mathrm{NO}$ on Day 8 and Day 15, morning trough $\mathrm{FEV}_{1}$ on Day 8 , and in morning and evening peak expiratory flow (mPEF, ePEF) over the treatment period. Patient reported outcomes for asthma control were assessed with the five item asthma control questionnaire (ACQ-5) recorded at each study visit. Asthma symptoms, night-time awakenings, rescue medication use and lung function as measured by morning and evening peak flow were recorded daily in the eDiary. Asthma symptoms were captured twice daily using a four point scale where patients recorded 0 for no symptoms and 3 if their asthma prevented them from doing normal daily activities or sleeping. The eDiary data was used to calculate the number of symptom free days, defined as those days on which no asthma symptoms or night-time awakenings occurred and the number of asthma control days which included the same criteria as symptom free days and no rescue medication use. The pharmacokinetic (PK) profile was also assessed as a secondary endpoint, with rich sampling in a subset of patients, blood samples were collected on Day 1 and Day 14 of each treatment period. PK parameters, $\mathrm{C}_{\max }$ and $\mathrm{AUC}_{0-24}$ were derived using non-compartmental methods with Phoenix ${ }^{\circ}$ WinNonlin $^{\circ}$ (Pharsight Corp., Mountain View, California, USA). In addition, the dose proportionality was assessed by dose normalized $\mathrm{C}_{\max }$ and $\mathrm{AUC}_{0-24}$ across three dose levels. A $24 \mathrm{~h}$ plasma cortisol profile was performed on Day - 1 and Day 14, in the PK subset, for each study period to obtain $\mathrm{AUEC}_{0-24}$ pre-treatment and post-treatment respectively, to evaluate cortisol suppression.

\section{Statistical analysis}

Thirty-six patients were needed to achieve approximately $88 \%$ power to detect $200 \mathrm{~mL}$ change from baseline in trough $\mathrm{FEV}_{1}$ compared to placebo using a two-sided test at 5\% significance level, assuming an intra-patient standard deviation (SD) of $210 \mathrm{~mL}$. Assuming a dropout rate of $25 \%, 48$ patients randomized to nine sequences were needed to ensure 36 evaluable patients completing the study.

The analysis of the efficacy endpoints was based on the full analysis set (FAS), defined as all randomized patients following the principle of intention to treat (ITT) that includes all randomized patients who received at least one dose of randomized study drug. Patients were included in the analysis according to the treatment to which they were randomized. All safety analyses were based on the safety analysis set (SAF) defined as all randomized patients who received at least one dose of randomized study drug during the Treatment Period. Classified by actual treatment received.

The efficacy endpoints were analyzed using a linear model with treatment, period, and sequence as fixed effects, baseline as continuous covariate, and patient within sequence as random effect. No multiplicity adjustment for the analysis of the secondary variables was performed. In addition, dose-response for trough $\mathrm{FEV}_{1}$ day 15 was analyzed posthoc using nonlinear mixed-effects modeling. In this analysis an empirical Emax model was estimated to the change from baseline trough $\mathrm{FEV}_{1}$ data, applying different baseline definitions (see Additional file 1). This study is registered with ClinicalTrials.gov , number NCT02479412.

\section{Results}

One hundred ten patients were enrolled and screened, 54 of whom were randomized. Thirty-four patients received AZD7594 $58 \mu \mathrm{g}, 34$ received AZD7594 $250 \mu \mathrm{g}, 34$ AZD7594 $800 \mu \mathrm{g}$ and 52 patients received placebo. Baseline demographics characteristics of participants were similar across treatment groups. (Table 1). Trough PK was 
Table 1 Baseline demographic and clinical characteristics

\begin{tabular}{|c|c|c|c|c|}
\hline & \multirow{2}{*}{$\begin{array}{l}\text { Placebo } \\
(n=52)\end{array}$} & \multicolumn{3}{|l|}{ AZD7594 } \\
\hline & & $58 \mu \mathrm{g}(n=34)$ & $250 \mu \mathrm{g}(n=34)$ & $800 \mu g(n=34)$ \\
\hline \multicolumn{5}{|l|}{ Demographics } \\
\hline Age, years Mean (SD) & $51(12)$ & $51(12)$ & $50(12)$ & $51(12)$ \\
\hline Male $n(\%)$ & $44(84.6 \%)$ & $26(76.5 \%)$ & $30(88.2 \%)$ & $28(82.3 \%)$ \\
\hline White $n(\%)$ & $51(98.1 \%)$ & $33(97.1 \%)$ & $33(97.1 \%)$ & $34(100 \%)$ \\
\hline Black $n(\%)$ & $1(1.92 \%)$ & $1(2.94 \%)$ & $1(2.94 \%)$ & $0(0.00)$ \\
\hline BMII kg/m² Mean (SD) & $27(3)$ & $27(4)$ & $28(3)$ & $27(3)$ \\
\hline \multicolumn{5}{|l|}{ Asthma Characteristics } \\
\hline Prebronchodilator FEV $1(\mathrm{~L})$, Mean (SD) & $2.53(0.74)$ & $2.54(0.73)$ & $2.59(0.72)$ & $2.55(0.69)$ \\
\hline$\%$ patients meeting $\mathrm{FEV}_{1}$ reversibility criteria ${ }^{\mathrm{a}}$ & $78.8 \%$ & $88.2 \%$ & $73.5 \%$ & $70.6 \%$ \\
\hline ACQ-5 score mean (SD) & $1.2(0.7)$ & $1.2(0.6)$ & $1.2(0.6)$ & $1.2(0.7)$ \\
\hline Asthma symptom score (SD) & $0.8(0.5)$ & $08(0.5)$ & $0.8(0.5)$ & $0.8(0.5)$ \\
\hline $\mathrm{F}_{\mathrm{E}} \mathrm{NO} \mathrm{ppb}(\mathrm{SD})$ & $57(45)$ & $60(47)$ & $53(34)$ & $57(39)$ \\
\hline
\end{tabular}

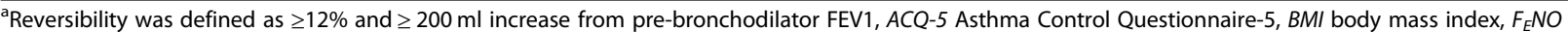
Fraction exhaled nitric oxide, $k g$ kilogram, $m$ meter, $S D$ standard deviation

collected in all study participants, 15 were included in an intensive PK sampling subset. Forty-eight patients (89\%) completed the study, four withdrew due to development of pre-specified study withdrawal criteria. and One patient was withdrawn due to randomization into the wrong PK group and one for an adverse event (vitamin B12 deficiency and elevated liver enzymes). Three patients had major protocol deviations and were excluded from the per protocol set (failed inclusion criteria, use of prohibited concomitant medication, and withdrawn without primary endpoint). Patients recorded daily in the eDiary if they took their study medication. Drug accountability records were kept by the investigator and remaining supplies, including spent capsules were sent to the sponsor. Across all treatment groups, mean compliance was $>96 \%$.

\section{Efficacy}

Lung function improved at all doses (Fig. 2). The greatest improvement in the primary endpoint, the change from baseline in morning trough $\mathrm{FEV}_{1}$ on Day 15 versus placebo, occurred with the $800 \mu \mathrm{g}$ dose (LS Means difference 0.148 L $95 \%$ CI 0.0349 to $0.261 p=0.011$ ) (Table 2).

The $800 \mu \mathrm{g}$ dose also showed the greatest improvement in change from baseline in morning trough $\mathrm{FEV}_{1}$ versus placebo on Day 8 (LSMeans difference $0.156 \mathrm{~L}$ $95 \% \mathrm{CI} 0.039$ to $0.273 p<0.01)$. The change from

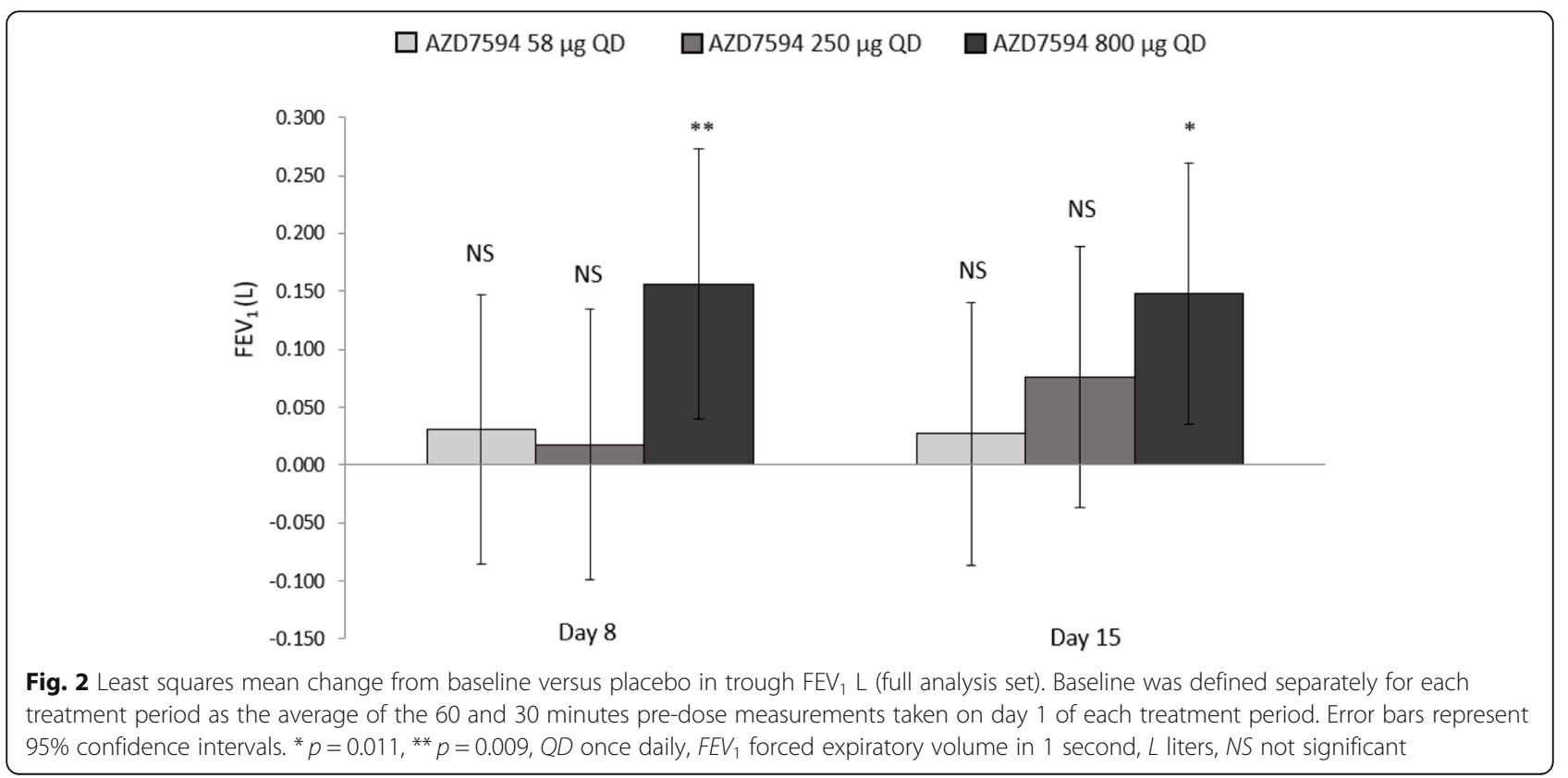


Table 2 Efficacy endpoints Least Squares Means full analysis set

\begin{tabular}{|c|c|c|c|c|}
\hline & $\begin{array}{l}\text { Placebo } \\
(n=52)\end{array}$ & 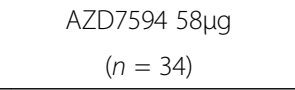 & $\begin{array}{l}\text { AZD7594 250 } \mathrm{gg} \\
\quad(n=34)\end{array}$ & $\begin{array}{l}\text { AZD7594 800 } \mu \mathrm{g} \\
\quad(n=34)\end{array}$ \\
\hline \multicolumn{5}{|l|}{ Primary efficacy endpoint } \\
\hline \multicolumn{5}{|l|}{ Morning pre-bronchodilator $\mathrm{FEV}_{1}$} \\
\hline Change from baseline (L) on day 15 & 0.059 & 0.086 & 0.136 & 0.207 \\
\hline Treatment difference (L) $(95 \% \mathrm{Cl})$ & N.A. & $0.027(-0.086,0.140)$ & $0.076(-0.036,0.188)$ & $0.148(0.035,0.261)$ \\
\hline$P$ value & N.A. & 0.638 & 0.183 & 0.011 \\
\hline \multicolumn{5}{|l|}{ Key secondary efficacy endpoints } \\
\hline \multicolumn{5}{|l|}{ Morning pre-bronchodilator $\mathrm{FEV}_{1}$} \\
\hline Change from baseline $(\mathrm{L})$ on day 8 & 0.071 & 0.102 & 0.089 & 0.227 \\
\hline Treatment difference (L) $(95 \% \mathrm{Cl})$ & N.A. & $0.031(-0.086,0.147)$ & $0.017(-0.010,0.134)$ & $0.156(0.039,0.273)$ \\
\hline$P$ value & N.A. & 0.604 & 0.767 & 0.009 \\
\hline \multicolumn{5}{|l|}{ Key secondary efficacy endpoints } \\
\hline \multicolumn{5}{|l|}{ Morning pre-bronchodilator $\mathrm{FEV}_{1}$} \\
\hline Change from baseline $(\mathrm{L})$ on day 8 & 0.071 & 0.102 & 0.089 & 0.227 \\
\hline Treatment difference (L) $(95 \% \mathrm{Cl})$ & N.A. & $0.031(-0.086,0.147)$ & $0.017(-0.010,0.134)$ & $0.156(0.039,0.273)$ \\
\hline$P$ value & N.A. & 0.604 & 0.767 & 0.009 \\
\hline \multicolumn{5}{|l|}{ Fraction exhaled nitric oxide ( $\left.\mathrm{F}_{\mathrm{E}} \mathrm{NO}\right)$} \\
\hline Change from baseline (ppb) on day 8 & -4.296 & -9.153 & -14.71 & -19.04 \\
\hline Treatment difference (ppb) (95\% Cl) & N.A. & $-4.857(-11.24,1.528)$ & $-10.41(-16.75,-4.075)$ & $-14.75(-21.18,-8.319)$ \\
\hline$P$ value & N.A. & 0.134 & 0.002 & $<0.0001$ \\
\hline Change from baseline (ppb) on day 15 & -0.549 & -14.40 & -14.81 & -20.44 \\
\hline Treatment difference (ppb) (95\% Cl) & N.A. & $-13.85(-24.06,-3.642)$ & $-14.26(-24.37,-4.149)$ & $-19.90(-30.10,-9.689)$ \\
\hline$P$ value & N.A. & 0.008 & 0.006 & 0.0002 \\
\hline \multicolumn{5}{|l|}{ Morning peak expiratory flow (mPEF) } \\
\hline Change from baseline Day 1-14 & 0.0814 & 10.42 & 5.334 & 12.60 \\
\hline Treatment difference (L/min) $(95 \% \mathrm{Cl})$ & N.A. & $10.34(-1.335,22.01)$ & $5.253(-6.427,16.93)$ & $12.52(0.748,24.29)$ \\
\hline$P$ value & N.A. & 0.082 & 0.374 & 0.037 \\
\hline \multicolumn{5}{|l|}{ Evening peak expiratory flow (ePEF) } \\
\hline Change from baseline Day 1-14 & -8.257 & 7.475 & 6.04 & 11.65 \\
\hline Treatment difference (L/min) (95\% Cl) & N.A. & $15.73(5.039,26.43)$ & $14.30(3.534,25.06)$ & $19.91(9.068,30.75)$ \\
\hline$P$ value & N.A. & 0.004 & 0.010 & 0.0004 \\
\hline \multicolumn{5}{|l|}{ Forced vital capacity (FVC) } \\
\hline Change from baseline $(\mathrm{L})$ on day 8 & 0.0844 & 0.062 & 0.084 & 0.153 \\
\hline Treatment difference (L) (95\% Cl) & N.A. & $-0.023(-0.137,0.091)$ & $-0.0003(-0.115,0.114)$ & $0.068(-0.046,0.183)$ \\
\hline$P$ value & N.A. & 0.694 & 0.996 & 0.240 \\
\hline Change from baseline $(L)$ on day 15 & 0.0765 & 0.042 & 0.104 & 0.138 \\
\hline Treatment difference (L) $(95 \% \mathrm{Cl})$ & N.A. & $-0.035(-0.141,0.072)$ & $0.028(-0.078,0.134)$ & $0.062(-0.045,0.168)$ \\
\hline$P$ value & N.A. & 0.521 & 0.598 & 0.254 \\
\hline \multicolumn{5}{|l|}{ Asthma symptom score } \\
\hline Change from baseline day $1-14$ & -0.012 & -0.119 & -0.094 & 0.215 \\
\hline Treatment difference (95\% Cl) & N.A. & $-0.107(-0.206,-0.008)$ & $-0.082(-0.182,0.018)$ & $-0.203(-0.303,-0.103)$ \\
\hline$P$ value & N.A. & 0.035 & 0.105 & 0.0001 \\
\hline \multicolumn{5}{|l|}{ Asthma symptom free days } \\
\hline Change from baseline day 1 - 14 & 0.050 & 0.603 & 0.318 & 1.01 \\
\hline
\end{tabular}


Table 2 Efficacy endpoints Least Squares Means full analysis set (Continued)

\begin{tabular}{|c|c|c|c|c|}
\hline & $\begin{array}{l}\text { Placebo } \\
(n=52)\end{array}$ & 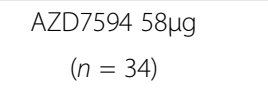 & $\begin{array}{l}\text { AZD7594 250 } \mu \mathrm{g} \\
\quad(n=34)\end{array}$ & $\begin{array}{l}\text { AZD7594 800 } \mu \mathrm{g} \\
\quad(n=34)\end{array}$ \\
\hline Treatment difference $(95 \% \mathrm{Cl})$ & N.A. & $0.553(0.036,1.069)$ & $0.268(-0.252,0.788)$ & $0.956(0.433,1.48)$ \\
\hline$P$ value & N.A. & 0.036 & 0.308 & 0.0005 \\
\hline \multicolumn{5}{|l|}{ Asthma control days } \\
\hline Change from baseline day $1-14$ & 0.277 & 0.950 & 0.705 & 1.219 \\
\hline Treatment difference (95\% Cl) & N.A. & $0.673(0.088,1.258)$ & $0.428(-0.161,1.017)$ & $0.942(0.348,1.535)$ \\
\hline$P$ value & N.A. & 0.025 & 0.152 & 0.002 \\
\hline \multicolumn{5}{|l|}{ ACQ-5 day 15} \\
\hline Change from baseline & 0.014 & -0.293 & -0.168 & -0.416 \\
\hline Treatment difference (95\% Cl) & N.A. & $-0.307(-0.516,-0.098)$ & $-0.182(-0.393,0.028)$ & $-0.430(-0.640,-0.221)$ \\
\hline$P$ value & N.A. & 0.004 & 0.088 & $<0.0001$ \\
\hline \multicolumn{5}{|l|}{ Rescue medication use (day 1 - 14) } \\
\hline Change from baseline (inhalations) per day & -0.334 & -0.678 & -0.819 & -1.137 \\
\hline Treatment difference (95\% Cl) & N.A. & $-0.344(-0.719,0.0318)$ & $-0.485(-0.863,-0.1073)$ & $-0.803(-1.183,-0.422)$ \\
\hline$P$ value & N.A. & 0.072 & 0.012 & $<0.0001$ \\
\hline \multicolumn{5}{|l|}{ Nighttime awakenings } \\
\hline Change from baseline day 1- 14 & 0.007 & -0.412 & -0.173 & -0.760 \\
\hline Treatment difference (95\% Cl) & N.A. & $-0.419(-0.741,-0.956)$ & $-0.179(-0.503,0.144)$ & $-0.766(-1.091,-0.441)$ \\
\hline$P$ value & N.A. & 0.0116 & 0.273 & $<0.0001$ \\
\hline
\end{tabular}

ACQ-5 Asthma Control Questionnaire-5, Cl confidence interval, FEV ${ }_{1}$ forced expiratory volume in 1 second, L liters, ppb parts per billion

baseline in $\mathrm{F}_{\mathrm{E}} \mathrm{NO}$ values demonstrated a dose ordered improvement (Fig. 3), with the $250 \mu \mathrm{g}$ and $800 \mu \mathrm{g}$ doses significant versus placebo at Day $8 p<0.05$ and a significant treatment difference across all doses at Day $15 \mathrm{p}<$ 0.01(Table 2). Over the course of the treatment period, evening PEF improved relative to placebo at all dose levels $(p<0.01)$ while morning peak flow was significantly improved only with the AZD7594 $800 \mu \mathrm{g}$ dose level (Fig. 4, Table 2). The greatest reduction in average (Day 1 to Day 14) daily use of rescue medication from baseline occurred at the $800 \mu \mathrm{g}$ dose (LS Means difference $-0.80 p<0.0001)$ and the $250 \mu \mathrm{g}$ dose also demonstrated a significant reduction $(-0.49 p=0.012)$. Asthma control improved, as evidenced by significant improvement in mean ACQ-5 score versus placebo at Day 15 in both the $58 \mu \mathrm{g}$ and $800 \mu \mathrm{g}$ doses, (Fig. 5). Both symptom free days and asthma control days as well as reduction in nighttime awakenings were significant versus placebo with AZD7594 $800 \mu \mathrm{g}$ (Table 2).

In the posthoc analysis, the dose-response in change from baseline trough $\mathrm{FEV}_{1}$ was described by an empirical Emax model (Additional file 1). An adequate fit could only be achieved when the average baseline across all periods was used. The $\mathrm{ED}_{50}$ was estimated to 140 [95\%CI 26-763] $\mu \mathrm{g}$, and the Emax to 0.213 [0.078-0.348] L. The model predicted trough $\mathrm{FEV}_{1}$ Day 15 versus placebo is shown in Additional file 1: Figure S1. The predicted effects are numerically larger, compared to the primary analysis.

\section{Pharmacokinetics}

Following inhalation administration, AZD7594 was rapidly absorbed and reached maximum plasma concentration within $15 \mathrm{~min}$; this was followed by a rapid decline in plasma concentration over $2 \mathrm{~h}$, and then a slow elimination phase. The observed AZD7594 concentration-over-time profiles for all three dose levels are shown in Fig. 6. The increases in AZD7594 mean systemic exposures $\left[\mathrm{C}_{\max }\right.$ and $\mathrm{AUC}_{0-24}$ values] were less than dose proportional as indicated by the dose-normalized values $\left(\mathrm{C}_{\max } / \mathrm{D}, \mathrm{C}_{\max , \mathrm{ss}} / \mathrm{D}\right.$ and $\left.\mathrm{AUC}_{(0-24) /} \mathrm{D}\right)$. There was moderate to high between-subject variability in AZD7594 PK parameters (Table 3). The geometric coefficient of variation (CV\%) ranged from 19.70 to $43.21 \%$ in $\mathrm{C}_{\max }$ (Days 1 and 14), and from 17.91 to $52.48 \%$ in $\mathrm{AUC}_{0-24}$.

\section{Safety and tolerability}

AZD7594 was well tolerated. Adverse events (AEs) were reported by 17 (32\%) of patients in the placebo group, $13(38 \%)$ of patients in the AZD7594 $58 \mu \mathrm{g}$ group, 9 $(26 \%)$ in the $250 \mu \mathrm{g}$ group and $12(35 \%)$ in the $800 \mu \mathrm{g}$ group (Table 4). There were no severe adverse events (SAEs) or deaths during the study. One patient was discontinued due to an $\mathrm{AE}$ of pernicious anemia (vitamin B12 deficiency anemia) and increased hepatic enzymes noted on the blood safety samples drawn at the end of the first washout period after receiving placebo in period 


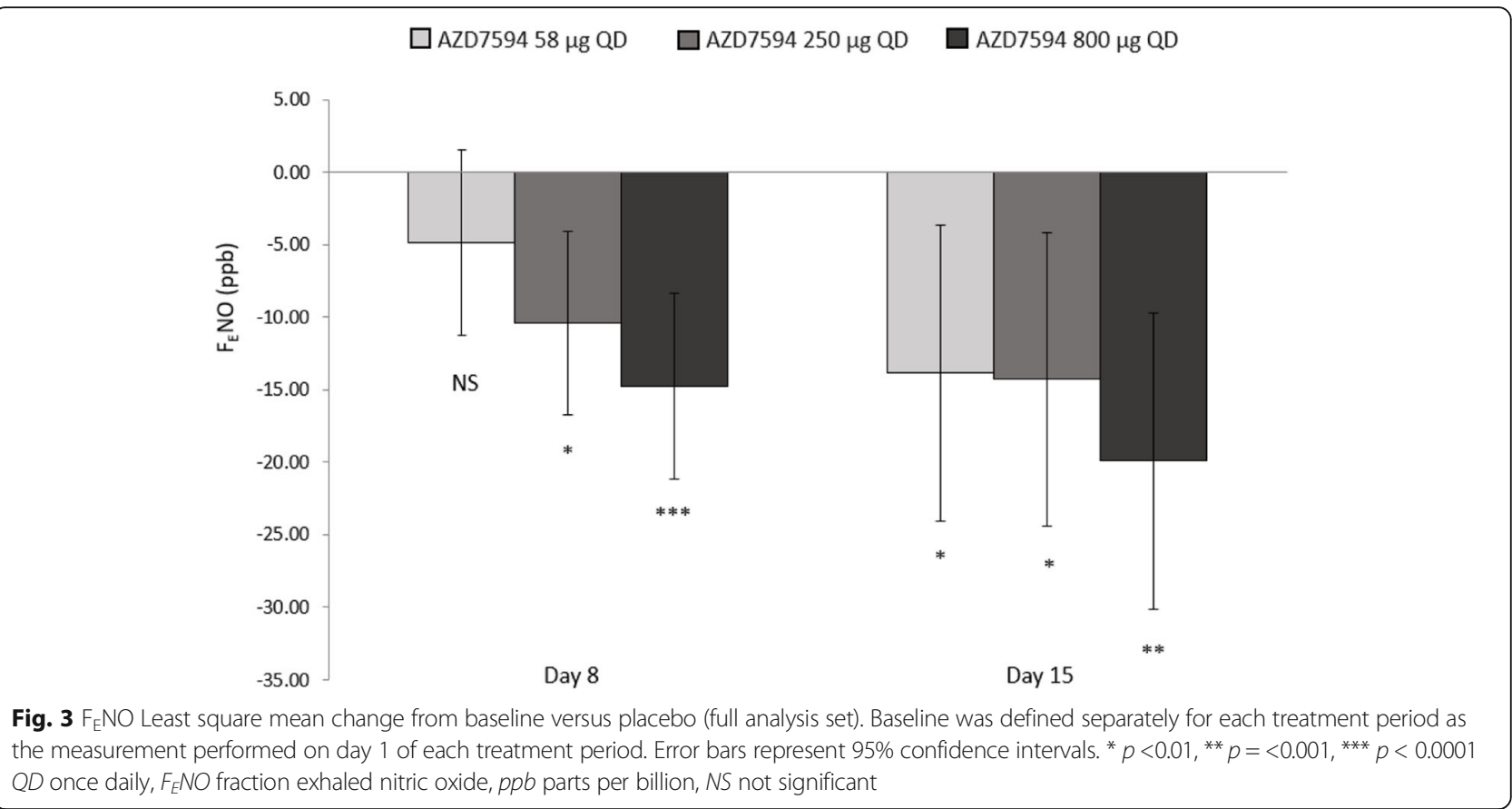

one. No clinically important differences were seen between treatments with regard to the number and overall pattern of patients reporting adverse events by system organ class. Adverse events are summarized in Table 4. Nasopharyngitis and headache were the most commonly reported AEs. No statistically significant difference in plasma cortisol level versus placebo was observed for any dose level of AZD7594, geometric mean ratio 1.03
(95\% CI 0.90-1.19) for $58 \mu \mathrm{g}, 1.02(0.88-1.18)$ for $250 \mu \mathrm{g}$ and $0.91(0.79-1.05)$ for $800 \mu \mathrm{g}$ (Table 5).

\section{Discussion}

This phase 2a study was the first to evaluate clinical efficacy of AZD7594 administered once daily via inhalation for 2 weeks in patients with mild to moderate asthma. AZD7594 reduced lung inflammation and improved

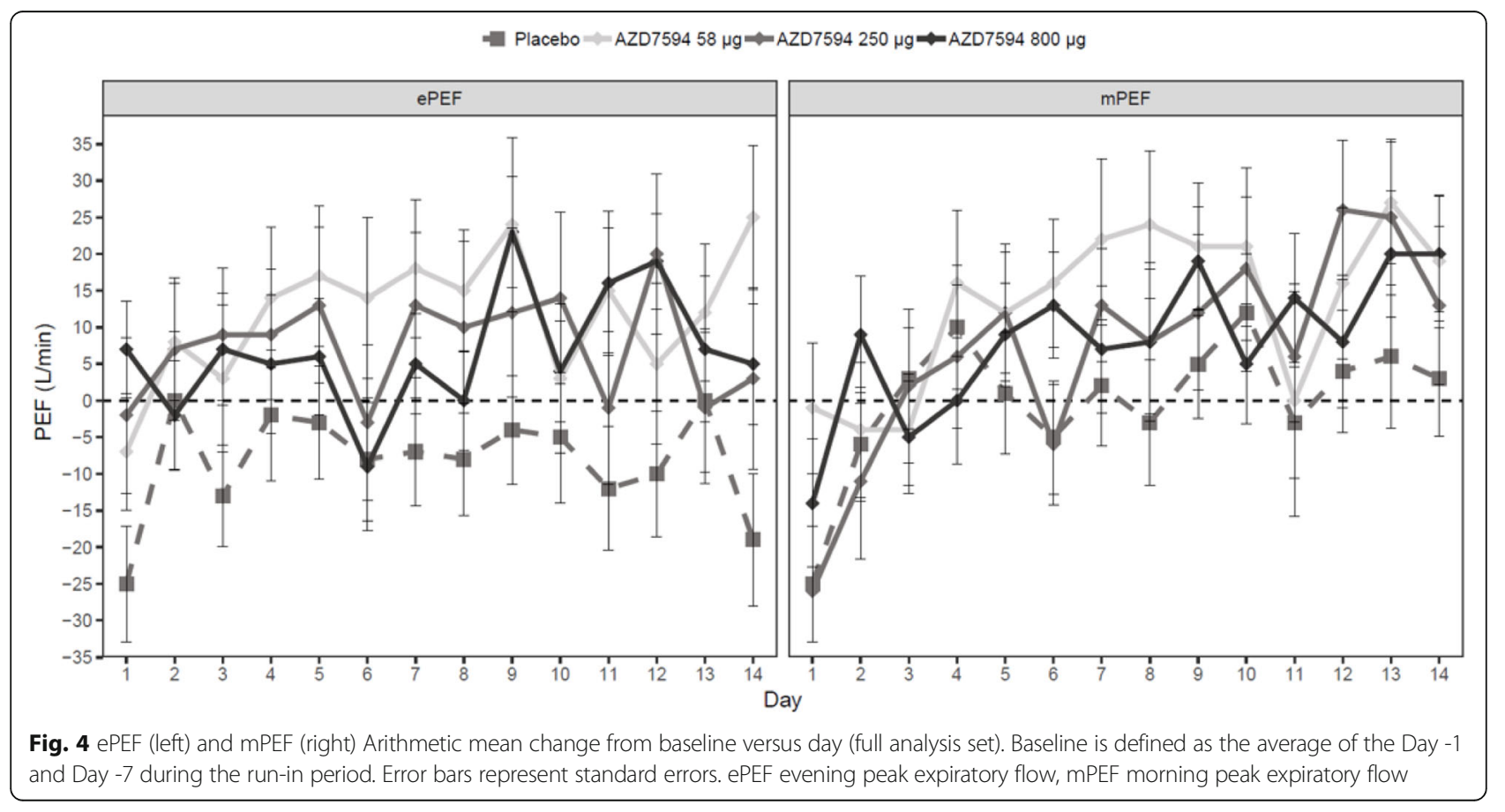




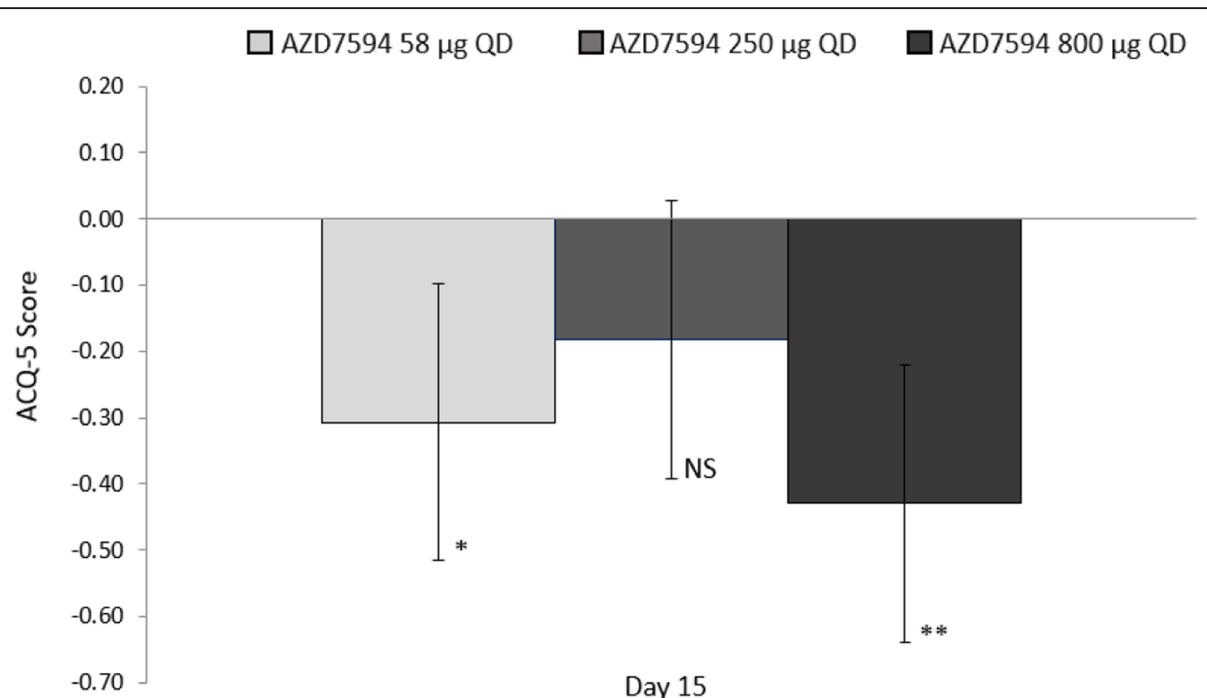

Fig. 5 ACQ-5 Least squares mean change from baseline versus placebo on Day 15 (full analysis set). Baseline was defined separately for each treatment period as the pre-dose score on day 1 of each treatment period. Error bars represent $95 \%$ confidence intervals. ${ }^{*} p<0.05$, ${ }^{* *} p<0.001$, NS not significant, QD once daily, ACQ-5 Asthma Control Questionnaire-5

lung function as evidenced by a clinically and statistically significant improvement in the primary endpoint, Day 15 trough $\mathrm{FEV}_{1}$ versus placebo at the $800 \mu \mathrm{g}$ dose, improved daily peak flow and asthma symptoms, reduced nocturnal awakenings and average daily rescue medication use.
Treatment with AZD7594 was associated with a significantly lower inflammatory burden as measured by $\mathrm{F}_{\mathrm{E}} \mathrm{NO}$ compared to placebo. $\mathrm{F}_{\mathrm{E}} \mathrm{NO}$ levels dropped in a dose-ordered manner at Day 8 and after 2 weeks of treatment all AZD7594 doses achieved a significant difference versus placebo $p<0.01$. A clinically meaningful

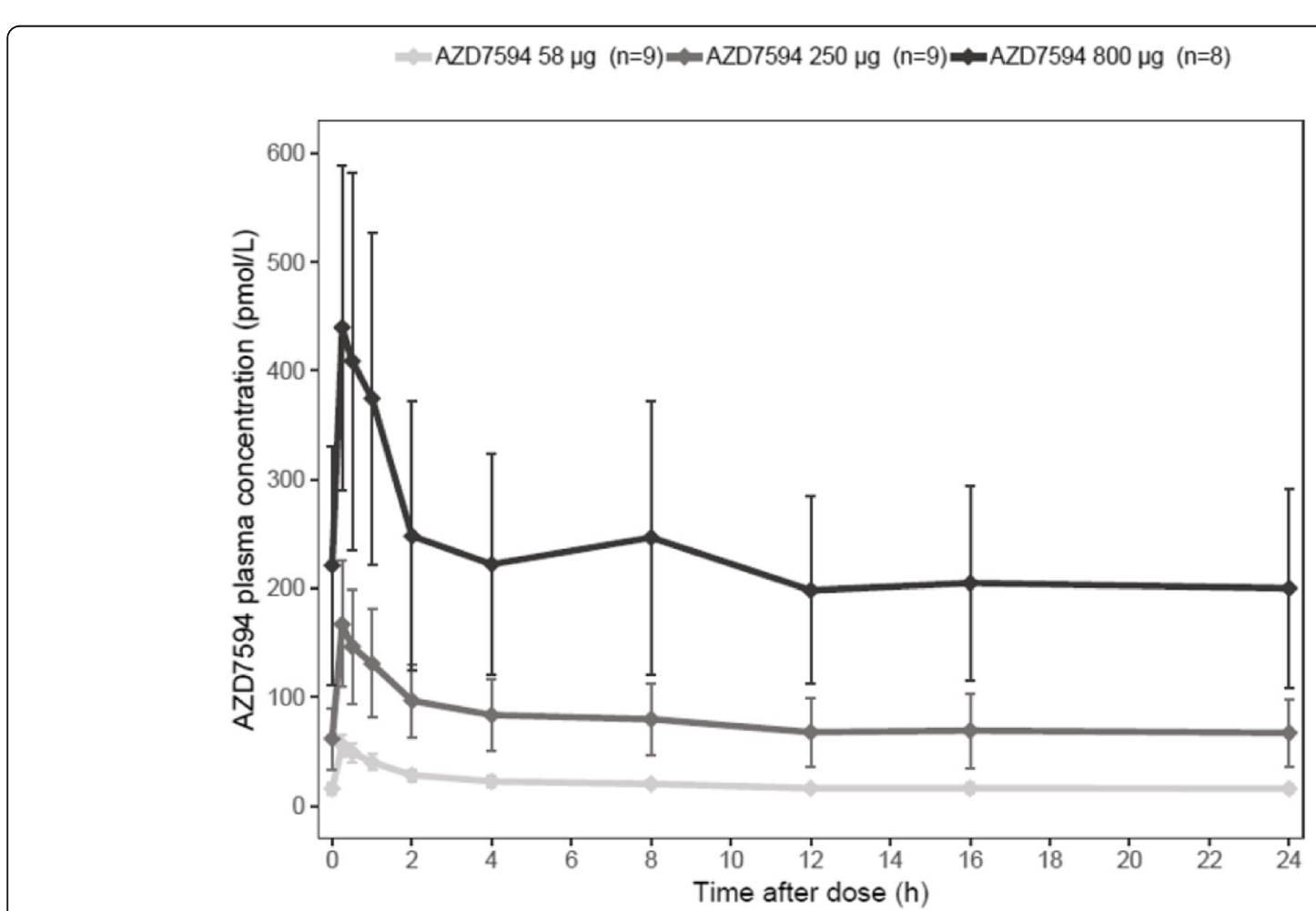

Fig. 6 AZD7594 Plasma concentrations at Steady-state (Day 14) Arithmetic means by dose level vs time after dose (pharmacokinetic analysis set). Error bars represent standard deviation. n: number of subjects 
Table 3 Summary of the PK Parameters of AZD7594 at SteadyState (Day 14) by Dose Levels

\begin{tabular}{llll}
\hline Geometric mean & AZD7594 & AZD7594 & AZD7594 \\
(CV\%) & $58 \mu \mathrm{g}$ & $250 \mu \mathrm{g}$ & $800 \mu \mathrm{g}$ \\
& $(n=9)$ & $(n=9)$ & $(n=8)$ \\
\hline Cmax, ss (pmol/L) & $54.97(19.70)$ & $158.7(35.01)$ & $421.6(37.26 \%)$ \\
AUC(0-24) (hxpmol/L) & $467.1(17.91)$ & $1725(44.33)$ & $4894(52.48 \%)$ \\
Cavg, ss (pmol/L) & $19.48(17.93)$ & $71.89(44.33)$ & $203.9(52.55 \%)$ \\
\hline
\end{tabular}

AUC(0-24): area under the plasma concentration-time curve from time zero to 24 hours after dose administration; Cavg,ss: average plasma concentration during a dosing interval at steady-state; Cmax,ss: observed maximum plasma concentration at steady-state; CV\%: geometric coefficient of variation; $n$ : number of patients in the PKS for each treatment

mean reduction of $>20 \%$ [15] was observed for all dose levels, with the greatest $\mathrm{F}_{\mathrm{E}} \mathrm{NO}$ reduction (35\%) occurring at the $800 \mu \mathrm{g}$ dose. As an effective biomarker of eosinophilic airway inflammation with a greater predictive value than spirometry and PEF in assessing ICS responsiveness in asthma, the clinical improvement observed, provides confidence in the anti-inflammatory properties of AZD7594 across a dose range $[15,16]$. Though this study measured many common asthma endpoints as well as $\mathrm{F}_{\mathrm{E}} \mathrm{NO}$ as marker of inflammation, other endpoints of interest for future studies include markers of inflammation in sputum, as well as direct measurement of bronchial hyperresponsiveness.

The objective of the study was to assess efficacy and tolerability across a wide dose range. Although the two lower doses did not significantly improve trough $\mathrm{FEV}_{1}$, there was a numerical improvement at all dose levels. A posthoc analysis conducted to gain a better understanding of dose-response showed a dose-dependent increase in trough $\mathrm{FEV}_{1}$, although the uncertainty in dose-response is large as can be expected for a GR agonist $[17,18]$. Lung function improved significantly at all doses as assessed by ePEF and at the $800 \mu \mathrm{g}$ dose for mPEF. Peak flow has the advantage over spirometry of being assessed daily. In this study, improvements in peak flow measurements were accompanied by a reduction in symptoms and nighttime awakenings and an increase in symptom free days, all important indicators of asthma control. The correlation of peak flow and asthma control has been previously reported [19].

In this study, ACQ- 5 scores improved significantly with both the low $(58 \mu \mathrm{g})$ and high $(800 \mu \mathrm{g})$ dose of AZD7594. Although improvement was shown, a conclusion regarding the clinically meaningful effect with this relatively small sample over a 2 week treatment cannot be drawn.

The current crossover study in a small number of subjects, was designed to assess the potential of AZD7594 as an anti-inflammatory treatment rather than fully characterize the clinical profile. A two part run in ensured appropriate patient selection for treatment with a GR agonist alone. By including patients who had an ACQ-5 of $\leq 1.5$ on low dose ICS as assessed during run in part one, we aimed to include patients at GINA step 2,3 [1]. Inclusion of patients who had a minimum $\mathrm{F}_{\mathrm{E}} \mathrm{NO}$ of $25 \mathrm{ppb}$ at the end of run-in part two enabled the enrollment of patients who demonstrated airway inflammation and were more likely to respond to a GR agonist; American Thoracic Society (ATS) guidelines suggest patients with $\mathrm{F}_{\mathrm{E}} \mathrm{NO}$ levels lower than $25 \mathrm{ppb}$ are unlikely to respond to GR agonist therapy [15]. The selection of a responder patient population provided more confidence in evaluating anti-inflammatory effect in a small number of subjects.

The 14-day treatment period allows adequate time to achieve clinical response. Previous studies demonstrate within 2 weeks near maximal improvement in lung function, as measured by $\mathrm{FEV}_{1},[2,20,21]$ and reduction of $\mathrm{F}_{\mathrm{E}} \mathrm{NO}$, a measure of airway inflammation. $[15,22,23]$. Lung function may have continued to improve with a longer treatment period. Personal best peak flow is typically reached within 1 to 3 weeks of initiating GR agonist therapy, but daily average peak flow may continue to improve for 3 months or more [24]. In future studies, a longer treatment period will be preferred to assess asthma control.

Table 4 Treatment emergent adverse events reported by $\geq 2$ patients in any dose level (safety analysis set)

\begin{tabular}{|c|c|c|c|c|}
\hline \multirow[t]{3}{*}{ Adverse Event } & Placebo & AZD7594 $58 \mu \mathrm{g}$ & AZD7594 $250 \mu \mathrm{g}$ & AZD7594 $800 \mu \mathrm{g}$ \\
\hline & $N=52$ & $N=34$ & $N=34$ & $N=34$ \\
\hline & n (\%) & n (\%) & n (\%) & n (\%) \\
\hline Patients with any $A E$ & $17(32.69)$ & $13(38.24)$ & $9(26.47)$ & $12(35.29)$ \\
\hline Nasopharyngitis & $8(15.38)$ & $4(11.76)$ & $2(5.88)$ & $4(11.76)$ \\
\hline Headache & $0(0.00)$ & $0(0.00)$ & $3(8.82)$ & $2(5.88)$ \\
\hline Gastroenteritis & $0(0.00)$ & $3(8.82)$ & $0(0.00)$ & $0(0.00)$ \\
\hline Diarrhoea & $0(0.00)$ & $0(0.00)$ & $0(0.00)$ & $3(8.82)$ \\
\hline Cough & $1(1.92)$ & $2(5.88)$ & $0(0.00)$ & $0(0.00)$ \\
\hline Dyspnoea & $2(3.85)$ & $0(0.00)$ & $0(0.00)$ & $0(0.00)$ \\
\hline
\end{tabular}


Table 5 AUECO-24 for plasma cortisol on Day 14

\begin{tabular}{llcl}
\hline Dose & $\mathrm{n}$ & $\begin{array}{l}\text { Geometric mean ratio to baseline } \\
\text { compared to placebo }(95 \% \mathrm{Cl})\end{array}$ & $p$-value \\
\hline placebo & 14 & $1.03(0.90-1.19)$ & 0.6342 \\
$58 \mu \mathrm{g}$ & 9 & $1.02(0.88-1.18)$ & 0.7620 \\
$250 \mu \mathrm{g}$ & 9 & $0.91(0.79-1.05)$ & 0.2008 \\
$800 \mu \mathrm{g}$ & 9 &
\end{tabular}

AUEC 0-24 Area under plasma concentration time curve from time zero to 24 hours after dose administration, $\mathrm{Cl}$ confidence Interval

The three-week washout was supported by the pharmacokinetic profile of AZD7594 [25], and glucocorticoid receptor agonist studies which demonstrate both $\mathrm{FEV}_{1}$ and $\mathrm{F}_{\mathrm{E}} \mathrm{NO}$ return to baseline levels within 14 to 21 days [20-22]. To limit the potential of any detectable carry-over effect, a baseline stability criterion was included for each period. The results should be interpreted with care since no correction for multiple testing was done for the secondary variables. For many of the secondary endpoints, the $250 \mu \mathrm{g}$ dose resulted in a lower response than the lowest dose. This is likely a result of variability and a small sample size, and dose-response modeling provides further support to select doses to investigate in the future studies.

Overall, in this study, AZD7594 was safe and well tolerated. The incidence of AEs was similar across treatment groups, the most common $\mathrm{AE}$ was nasopharyngitis. While cortisol suppression has been seen at higher doses of AZD7594 [26], only limited cortisol suppression was observed at the highest dose in this study, no significant difference versus placebo was observed. The absence of candidiasis and dysphonia in all patients is encouraging but a longer treatment period is needed to more fully assess the adverse effect profile.

Although the current study met its objective of assessing short term efficacy and safety of AZD7594, a parallel design study over a longer treatment period in broader patient population is needed to adequately assess the minimally efficacious and optimal doses. A novel once daily inhaled non-steroidal glucocorticoid modulator with an improved therapeutic risk-benefit profile would be a welcome addition to current asthma therapies, further clinical studies, including comparison to an active ICS comparator, are needed to fully characterize AZD7594.

\section{Conclusions}

In this phase 2a study, the first to evaluate clinical efficacy in patients with mild to moderate asthma, once daily inhaled administration of AZD7594, a novel non-steroidal selective GR modulator demonstrates improved lung function as measured by $\mathrm{FEV}_{1}$ and PEF, a reduction of airway inflammation as evidenced by a reduction in $\mathrm{F}_{\mathrm{E}} \mathrm{NO}$ and a positive impact on symptoms and asthma control. AZD7594 was well tolerated with an adverse effect profile similar to placebo. This study supports that a once daily inhaled non-steroidal SGRM is effective and well tolerated and may provide an alternative to ICS for patients in the future. Further clinical work is required to fully characterize the clinical profile and compare to currently available ICS.

\section{Additional file}

Additional file 1: Supplementary appendix. (PDF 175 kb)

\section{Abbreviations}

ACQ-5: Asthma Control Questionnaire-5; AE: Adverse Effect; AMP: Adenosine monophosphate; ATS: American Thoracic Society; AUC(0-24): Area under the plasma concentration-time curve from time zero to 24 hours after dose administration; AUEC(0-24): Area under the effect curve from time zero to 24 hours after dose administration; BID: Twice daily; Cl: Confidence interval; Cmax: Observed maximum plasma concentration; Cmax, ss: Observed maximum plasma concentration at steady-state; Cmax, ss/D: Dosenormalized observed maximum plasma concentration at steadystate; Cmax/ D: Dose-normalized observed maximum plasma concentration;

CV\%: Geometric coefficient of variation; DPI: Dry powder inhaler; [ED]50: Dose that produces the desired therapeutic effect in 50\% of the patients; Emax: Maximum effect; ePEF: Evening peak expiratory flow; FAS: Full Analysis Set; $F_{E} N O$ : Fractional exhaled nitric oxide; $F_{E V}$ : Forced expiratory volume in 1 second; GINA: Global Initiative for Asthma; GR: Glucocorticoid receptor; HPA: Hypothalamic-pituitary-adrenal; ICS: Inhaled corticosteroids; IEC: Independent Ethics Committee; IRB: Institutional Review Board; ITT: Intention to treat; L: Liter; LABA: Long-acting $\beta$-2 agonist; mPEF: Morning peak expiratory flow; PEF: Peak expiratory flow; PK: Pharmacokinetic; ppb: Parts per billion; SABA: Short-acting $\beta-2$ agonist; SAE: Serious Adverse Effect; SAF: Safety Analysis Set; SD: Standard deviation; SGRM: Selective glucocorticoid receptor modulator

\section{Acknowledgements}

We thank the patients and their carers, as well as the investigators and site staff who participated in this study. AstraZeneca develops and markets treatments for asthma. AZD7594 is an investigational medical product with no approved indication.

\section{Funding}

This study was sponsored and funded by AstraZeneca.

The sponsor of the study had a role in study design, data collection, data analysis, data interpretation, and the writing of the report. AstraZeneca reviewed the publication, without influencing the opinions of the authors, to ensure medical and scientific accuracy, and the protection of intellectual property. The corresponding author had full access to all the data in the study and had final responsibility for the decision to submit for publication.

\section{Availability of data and materials}

Data underlying the findings described in this manuscript may be obtained in accordance with AstraZeneca's data sharing policy described at https:// astrazenecagrouptrials.pharmacm.com/ST/Submission/Disclosure.

\section{Authors' contributions}

$A A, H S, Y C, H F, M B, R F, J B, H J$ provided input into the study design, $A A, H S$, $Y C, H F, M B, R F, J B, U W H, H J$ contributed to the analysis and interpretation. Study conduct and data collection was performed by AA, RF, JB, HF. HS contributed to statistical analysis. UWH conducted the dose-response post hoc analysis. MB, AA, HS and YC wrote the first draft of the manuscript. All authors contributed to the revision and approved the final version before submission.

\section{Ethics approval and consent to participate}

The study protocol was approved by the Institutional Review Board (IRB) or Independent Ethics Committee (IEC) at each center. The study 
(NCT02479412) was done in accordance with the Declaration of Helsinki, the International Council of Harmonisation guidelines for good clinical practice, and applicable regulatory requirements. All patients provided written informed consent before being enrolled in the study.

\section{Consent for publication}

\section{Not applicable.}

\section{Competing interests}

$M B, Y C, H F, U W H$ are current employees of AstraZeneca, AA and HS are former employees of AstraZeneca and own stock, and $\mathrm{HJ}$ is a former employee of AstraZeneca and does not own stock. JB has received consultancy and speaking fees from AstraZeneca RF is an employee of PAREXEL. AstraZeneca provided funding to PAREXEL for the conduct of this study.

\section{Publisher's Note}

Springer Nature remains neutral with regard to jurisdictional claims in published maps and institutional affiliations.

\section{Author details}

${ }^{1}$ Respiratory, Inflammation and Autoimmunity Translational Medicine Unit, Early Clinical Development, IMED Biotech Unit, AstraZeneca, 35 Gatehouse Drive, Waltham, MA 02451, USA. PAREXEL, International GmbH House 18, Klinikum Westend, Spandauer Damm 130, 14050 Berlin, Germany. ${ }^{3}$ insaf Respiratory Research Institute GmbH, Villa Berg Biebricher Allee 34, D-65187 Wiesbaden, Germany. ${ }^{4}$ Biometrics, Early Clinical Development, IMED Biotech Unit, AstraZeneca, 35 Gatehouse Drive, Waltham, MA 02451, USA. ${ }^{5}$ Quantitative Clinical Pharmacology, Early Clinical Development, IMED Biotech Unit, AstraZeneca, 35 Gatehouse Drive, Waltham, MA 02451, USA. ${ }^{6}$ Quantitative Clinical Pharmacology, Early Clinical Development, IMED Biotech Unit, AstraZeneca, SE-43183 Gothenburg, Mölndal, Sweden. ${ }^{7}$ Respiratory, Inflammation and Autoimmunity Translational Medicine Unit, Early Clinical Development, IMED Biotech Unit, AstraZeneca, SE-43183 Gothenburg, Mölndal, Sweden. ${ }^{8}$ Respiratory, Inflammation and Autoimmunity IMED Biotech Unit, AstraZeneca, SE-43183 Gothenburg, Mölndal, Sweden.

Received: 15 October 2018 Accepted: 5 February 2019

Published online: 18 February 2019

\section{References}

1. GINA 2018 Global strategy for asthma management and prevention. Updated 2018. Available from http://www.ginasthma.org/ accessed 29 Mar 2018.

2. Noonan M, Rosenwasser LJ, Martin P, O'Brien CD, O'Dowd L. Efficacy and safety of budesonide and formoterol in one pressurized metered-dose inhaler in adults and adolescents with moderate to severe asthma. A randomized clinical trial. Drugs. 2006;66(17):2235-54.

3. Lotvall J, Bleeker ER, Busse WW, O'Byrne PM, Woodcock A, Kerwin EM, et al. Efficacy and safety of fluticasone Furoate $100 \mu \mathrm{g}$ once-daily in patients with persistent asthma: a 24-week placebo and active controlled randomized trial. Respir Med. 2014;108:41-9.

4. Nathan RA, Nolte H, Pearlman DS. Twenty-six-week efficacy and safety study of mometasone Furoate / formoterol 200/10 $\mu \mathrm{g}$ combination treatment in patients with persistent asthma previously receiving medium-dose inhaled corticosteroids. Allergy and Asthma Proc. 2010;31(4):269-79.

5. Kelly W, Sternberg A, Lescher R, Fuhlbrigge A, Willaims P, Zeiger R, et al And the CAMP research group. Effect of inhaled glucocorticoids in childhood on adult height. N Engl J Med. 2012;367(10):904-12.

6. Pruteanu Al, Chauhan BF, Zhang L, Prietsch S, Ducharme FM. ICS in children with persistent asthma: dose response effects on growth. Cochrane Database Sys Rev, 2014 issue 7.

7. Lung Health Study Research Group. Effect of inhaled triamcinolone on the decline in pulmonary function in chronic obstructive pulmonary disease. N Engl J Med. 2000;343(26):1902-9.

8. Ferguson $G$, Calverley P, Anderson J, Jenkins C, Jones P, Willits L, et al. Prevalence and progression of osteoporosis in patients with COPD. Results from the TORCH study. CHEST. 2009;136:1456-65.

9. Christensson C, Thoren A, Lindberg B. Safety of inhaled budesonide. Drug Saf. 2008;31(11):965-88

10. Pandya D, Puttanna A, Balagopal V. Systemic effects of inhaled corticosteroids: an overview. Open Respir Med J. 2014;8:59-65.
11. Westergaard CG, Porsbjerg C, Baker V. Emerging corticosteroid agonists for the treatment of asthma. Expert Opinion Emerging Drugs. 2015;20(4):653-62.

12. Karrman Mardh C, Russel W, Gustavsson M, Kurian N, Jansson A, Smailagic A, Edman K. A novel inhaled non-steroidal modulator of inflammation for the control of asthma; AZD7594. Am J Respir Crit Care Med. 2016;193:A1329.

13. Brown M, Fuhr R, Su H, Chen Y, Forsman H, Jackson H, Aggarwal A. A randomized trial of AZD7594 a novel non-steroidal anti-inflammatory drug in asthma patients. Presentation September 10, 2017 European Respiratory Society 2017, Milan Italy.

14. Akkermans R; Annual Congress of the European Respiratory Society; Lancet Respir Med 2017, 2017, S2213-S2600(17)30374.

15. Dweik R, Boggs P, Erzurum S, Irvin C, Leigh M, Lundberg J, et al. An official ATS clinical practice guideline: interpretation of FeNO for clinical applications. Am J Respir Crit Care Med. 2011;184:602-15.

16. Donohue J, Jain N. Exhaled nitric oxide to predict corticosteroid responsiveness and reduce asthma exacerbation rates. Respir Med. 2013;107:943-52.

17. Masoli M, Holt S, Weatherall M, Beasley R. Dose-response relationship of inhaled budesonide in adult asthma: a meta-analysis. Eur Respir J. 2004;23:552-8.

18. Holt S, Suder A, Weatherall M, Cheng S, Shirtcliffe P, Beasley R. Doseresponse relation of inhaled fluticasone propionate in adolescents and adults with asthma: meta-analysis. Br Med J. 2001;323:1-8.

19. Peters SP, Kunselman SJ, Icitovic N, Moore W, Pascual R, Ameredes B, et al. For the NHLBI asthma clinical research network. Tiotropium bromide step-up therapy for adults with uncontrolled asthma. N Engl J Med. 2010;363:1715-26.

20. Gershman N, Wong H, Liu J, Fahy J. Low and high-dose fluticasone propionate in asthma; effects during and after treatment. Eur Respir J. 2000;15:11-8.

21. Phillips K, Oborne J, Lewis S, Harrison TW, Tattersfield AE. Time course of action of two inhaled corticosteroids, fluticasone propionate and budesonide. Thorax. 2004;59:26-30.

22. van Rensen $E$, Straathof $K$, Veselic-Charvat M, Zwinderman A, Bel E, Sterk $P$. Effect of inhaled steroids on airway hyperresponsiveness, sputum eosinophils, and exhaled nitric oxide levels in patients with asthma. Thorax. 1999:54:403-8.

23. Reid D, Johns D, Feltis B, Ward C, Walters E. Exhaled nitric oxide continues to reflect airway hyperresponsiveness and disease activity in inhaled corticosteroid-treated adult asthmatic patients. Respirology. 2003;8:479-86.

24. Reddel HK, Marks GB, Jenkins CR. When can personal best peak flow be determined for asthma action plans? Thorax. 2004;59:922-4.

25. Chen Y, Prothon S, Su H, Brown MN, Forsman H, Jackson H, et al. Pharmacokinetics (PK) of a single dose of AZD7594 administered intravenously (IV), orally and inhaled via two dry powder inhalers (DPI) and a pressurized metered-dose inhaler (pMDI) European Respiratory Society, Milan poster presentation September 10, 2017 A531.

26. Chen Y, Prothon S, Aurivillius M, Eriksson U, Aggarwal A. Safety, tolerability, pharmacokinetics, and pharmacodynamics of AZD7594 after single and multiple ascending inhaled doses in healthy male volunteers. Am Soc Clinical Pharmacol and Ther. 2016;99(S1):S5-S107 Abstract PI-033.

Ready to submit your research? Choose BMC and benefit from:

- fast, convenient online submission

- thorough peer review by experienced researchers in your field

- rapid publication on acceptance

- support for research data, including large and complex data types

- gold Open Access which fosters wider collaboration and increased citations

- maximum visibility for your research: over $100 \mathrm{M}$ website views per year

At $\mathrm{BMC}$, research is always in progress.

Learn more biomedcentral.com/submissions 